\title{
Avaliação do sistema de microdrenagem visando à sustentabilidade de área urbana com problemas de alagamentos e influência das marés
}
Assessment of the micro-drainage system to the sustainability of urban area with tidal influence and flooding problems

Evaluación del sistema micro drenaje a la sostenibilidad de área urbana con problemas de inundaciones y mareas

\section{Marcos Antonio Barbosa da Silva Junior Mestre em Engenharia Civil, UPE, Brasil. marcos15barbosa@hotmail.com.br}

Simone Rosa da Silva Professora Doutora, UPE, Brasil. simonerosa@poli.br

Roberta de Melo Guedes Alcoforado Professora Doutora, UPE, Brasil. ralcoforado@projetecnet.com.br 


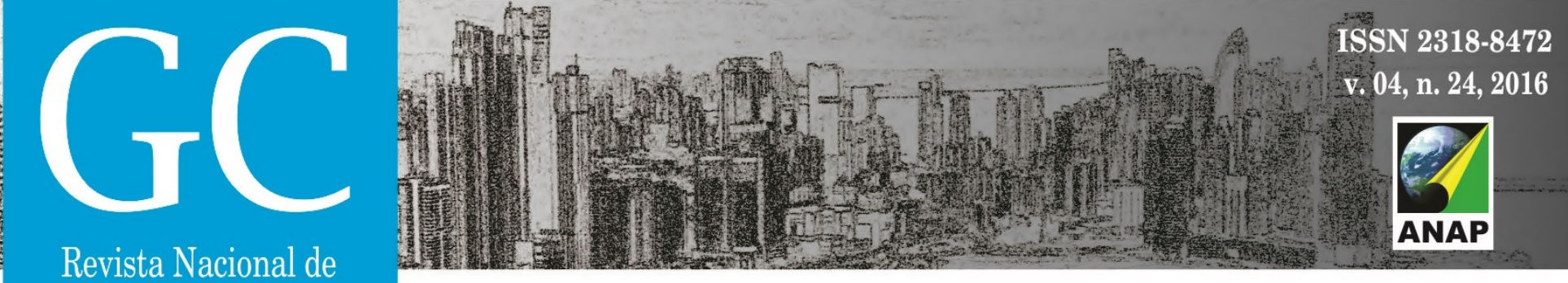

Gerenciamento de Cidades

\section{INTRODUÇÃO}

O processo de urbanização acelerado e não planejado das cidades tem apresentado grandes mudanças no meio ambiente, acarretando sérios problemas para a infraestrutura urbana.

Um dos impactos decorrentes deste desenvolvimento acelerado está relacionado à drenagem das águas pluviais, caracterizado pelos alagamentos nos centros urbanos na ocorrência de chuvas. Entretanto, outros problemas, como poluição de mananciais e erosão, também estão relacionados diretamente com a urbanização e a drenagem pluvial (SILVA, 2006).

Yannopoulos (2013) enfatiza que este processo produz o aumento e a aceleração do escoamento superficial das águas pluviais, além de diminuir a capacidade de infiltração da água no solo.

Essa situação se agrava principalmente nas planícies costeiras, como é o caso da cidade do Recife, que teve seu processo de ocupação urbana de forma desordenada e possui um sistema de drenagem altamente vulnerável às oscilações de maré, podendo provocar sérios problemas de alagamentos em períodos de chuvas intensas combinados com maré alta (SILVA JÚNIOR, 2015).

\section{OBJETIVOS}

Diante das peculiaridades urbanísticas e geográficas apresentadas pela cidade, atualmente o Recife apresenta 159 pontos de alagamentos, catalogados pela Emlurb (Empresa de Manutenção e Limpeza Urbana), como os mais críticos. Com base neste cenário, o presente trabalho consiste em avaliar o sistema de microdrenagem de um destes pontos de alagamento, identificando as principais causas associadas ao problema e propondo melhorias para adequação da rede de drenagem local.

\section{METODOLOGIA / MÉTODO DE ANÁLISE}

Em linhas gerais, a avaliação proposta para o sistema de microdrenagem da área estudada foi conduzida a partir das seguintes fontes de informação:

- Articulação com técnicos da Prefeitura do Recife: Foram procedidas reuniões com técnicos da Emlurb, órgão responsável pela gestão da drenagem urbana na cidade, para a definição do ponto crítico, obtenção de dados topográficos e cadastrais da rede de drenagem na área estudada, que fundamentaram a análise.

- Visitas de campo: Foram realizadas duas vistorias no local, sendo uma durante o período seco e a outra no período chuvoso. No período seco foram identificados, fotografados e mapeados os principais elementos de drenagem com interferência direta ao ponto crítico de alagamento. O período chuvoso foi acompanhado no seu momento mais intenso de precipitação, observando as alturas de lâmina d'água e a 


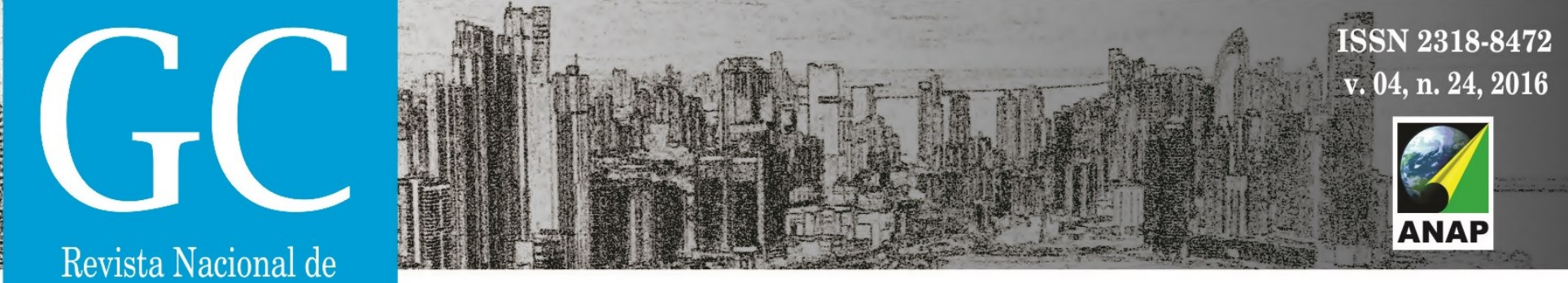

Gerenciamento de Cidades

extensão do alagamento provocado em decorrência do evento de precipitação considerado.

\section{DISCUSSÃO}

\section{a) Estudo de Caso}

O ponto crítico de alagamento, objeto de análise deste artigo, está localizado no bairro da Soledade, município do Recife, mais especificamente no cruzamento da Avenida João de Barros com a Rua Joaquim Felipe. Para a consolidação deste estudo, foi necessário analisar o incremento do volume de escoamento provocado pela urbanização, a montante do ponto crítico em questão. Assim, outros bairros vizinhos ao bairro da Soledade (Boa Vista e Santo Amaro) foram considerados na análise.

Desde a sua origem, as cidades vão passando por transformações, e no Recife não tem sido diferente. A partir do novo desenho dos bairros, em 1988 surgiu o bairro da Soledade, cuja área pertencia ao bairro da Boa Vista. Segundo o Plano Diretor da Cidade do Recife, em 1996, o bairro da Boa Vista possuía a segunda maior área construída do Recife $\left(832.808 \mathrm{~m}^{2}\right)$, e o bairro de Santo Amaro, a quarta maior área construída (535.696 $\left.\mathrm{m}^{2}\right)$.

No entanto, levando em consideração o ano 2003, o bairro de Santo Amaro apresentou um crescimento de $49 \%$ de área construída, e o bairro da Boa Vista, um crescimento inferior a $20 \%$. Já o bairro da Soledade, de acordo com o Censo do IBGE (2000) e dados da Prefeitura do Recife, é predominantemente residencial, com 1.257 imóveis, seguido por 477 imóveis não residenciais e 352 terrenos. A Tabela 1 mostra a área e a variação populacional dos bairros de Santo Amaro, Boa Vista e Soledade, em 1991, 2000 e 2010.

Tabela 1: Área e evolução populacional dos bairros de Santo Amaro, Boa Vista e Soledade.

\begin{tabular}{ccccc}
\hline Bairros & Área (ha) & $\mathbf{1 9 9 1}$ & População (hab.) & $\mathbf{2 0 1 0}$ \\
\hline Santo Amaro & 380 & 30.095 & 2900 & 27.939 \\
\hline Boa Vista & 176 & 17.059 & 14.033 & 14.778 \\
\hline Soledade & 32 & 2.882 & 2.201 & 2.495 \\
\hline
\end{tabular}

Fonte: Censos do IBGE 1991, 2000 e 2010.

Diante do crescimento acelerado na área de montante ao ponto de alagamento, grande parte das áreas permeáveis foi se tornando impermeável, tendo como consequência a diminuição da capacidade de infiltração e o aumento do escoamento superficial pelas ruas e avenidas. Além disso, a infraestrutura de drenagem não acompanhou o processo de urbanização dessas áreas, tornando-a ineficiente diante da sobrecarga das tubulações existentes com vistas na realidade atual. Por causa disto, em períodos chuvosos ocorrem alagamentos que se concentram na Avenida João de Barros, próximo à Rua Joaquim Felipe. 


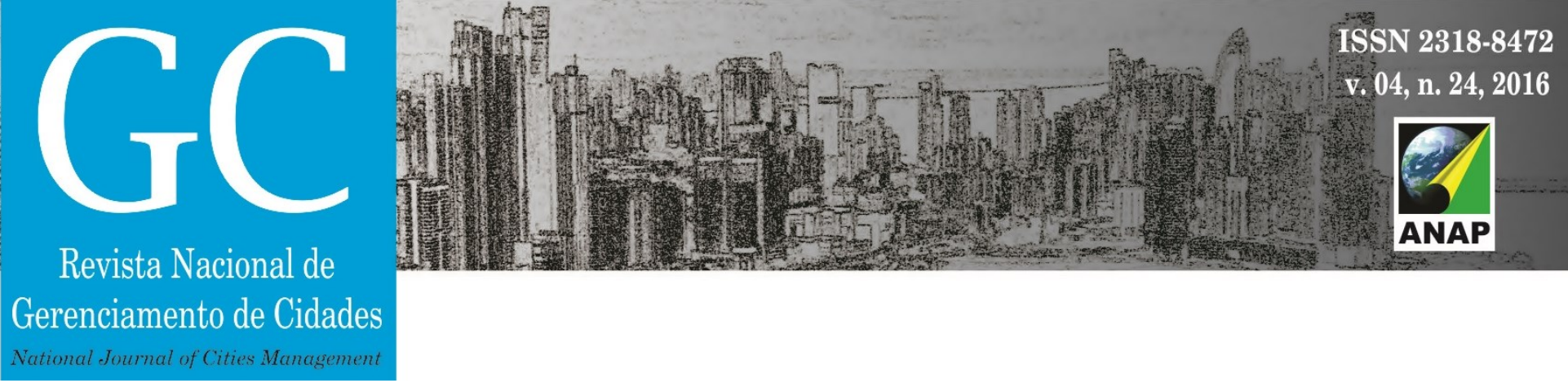

Figura 5: Sequência de imagens de alagamentos na área em estudo.

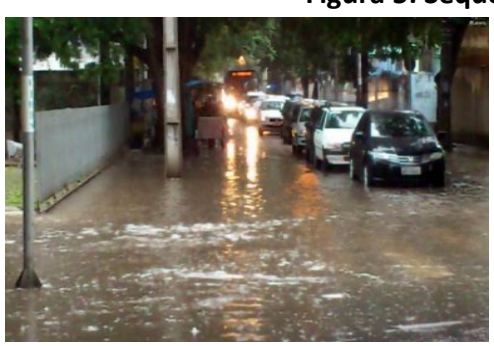

Alagamento provocado pela chuva do dia 15/07/2013.

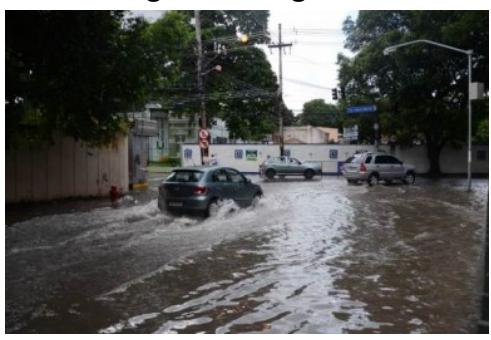

Alagamento provocado pela chuva do dia 05/06/2013.

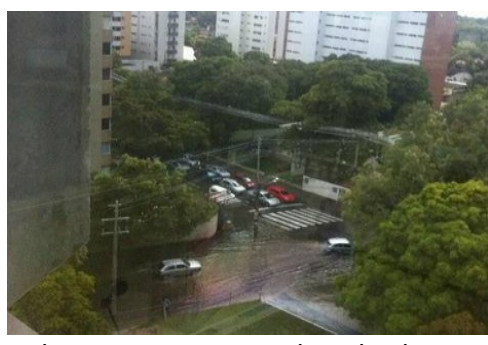

Alagamento provocado pela chuva do dia 24/04/2013.

Fonte: FolhaPE; LeiaJá; JConline.

\section{b) Diagnóstico da rede de drenagem existente}

Foram realizadas visitas com o intuito de reconhecer a área em estudo e verificar as causas dos alagamentos que ocorrem atualmente. Foram percorridos toda a Rua Joaquim Felipe e um trecho da Avenida João de Barros até a Rua do Príncipe, para identificar os elementos de drenagem e suas atuais condições (Figura 6). Na ocasião da visita, também foi possível obter informações de alguns moradores e comerciantes da área, com detalhes sobre os transtornos causados em dias de chuvas na área em questão. Segundo eles, nos períodos de chuva a altura de alagamento chega próxima dos $30 \mathrm{~cm}$, fazendo com que alguns comerciantes aumentassem o nível do piso de seu comércio em relação à calçada (Figura 7). Além disso, com o alagamento da via, que ultrapassa o nível da calçada, é vetada a possibilidade dos pedestres transitarem na área, tendo que utilizar o jardim do prédio da Celpe para se deslocar.

Figura 6: Av. João de Barros com a Rua Joaquim Felipe.

Figura 7: Nível do piso em relação à calçada.
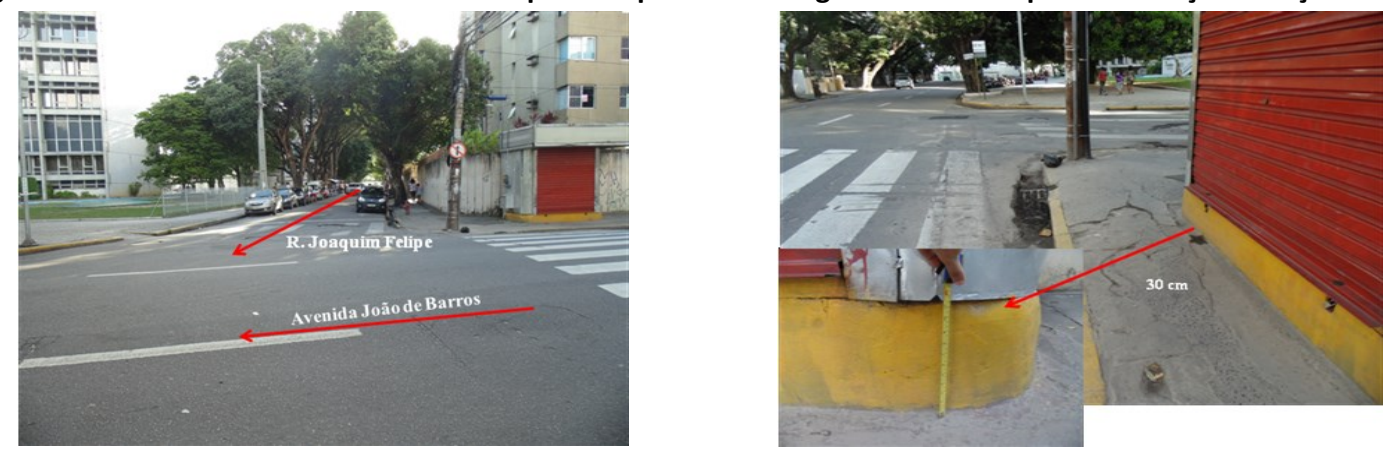

A Rua Joaquim Felipe é um importante eixo viário e possui um tráfego intenso, pois liga outras vias importantes, como a Avenida Agamenon Magalhães e Avenida João de Barros. Durante os eventos de chuva, com a ocorrência de alagamentos, os veículos passam com dificuldades, causando congestionamento no local. 


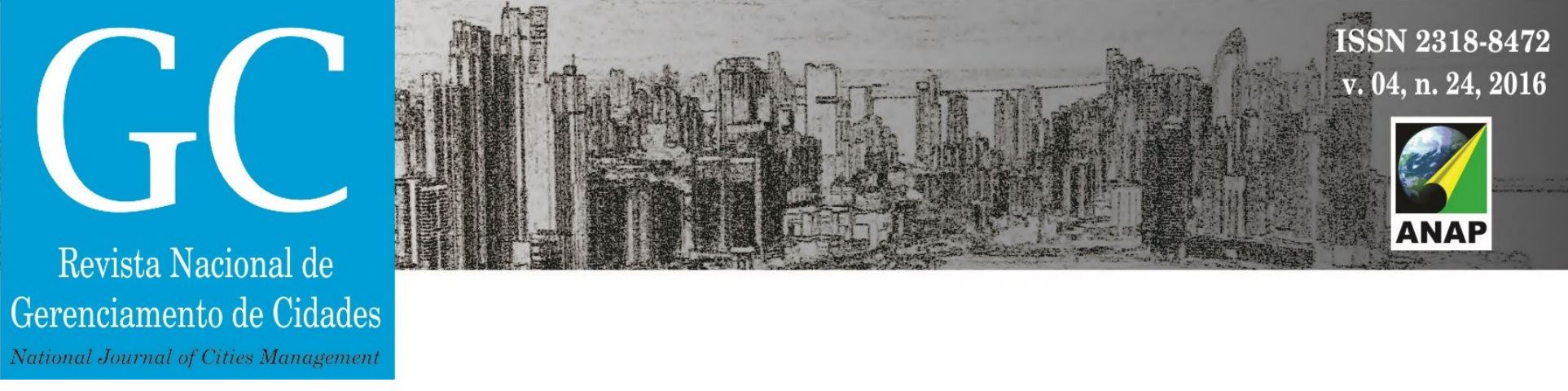

Segundo o cadastro da rede de drenagem da Prefeitura do Recife, cedido pela Emlurb, a rua em questão, com extensão de 250 metros, possui apenas 55 metros de galerias com diâmetro de $300 \mathrm{~mm}$, que se ligam à rede de drenagem da Avenida João de Barros, com diâmetro de $400 \mathrm{~mm}$, e o trecho restante da via possui drenagem superficial através das sarjetas. Isso se deve ao fato de que, segundo técnicos da Emlurb, a citada rua possui uma câmara subterrânea de telefonia da antiga Telpe, que abrange toda a largura da rua, impossibilitando a implantação de um sistema de drenagem por galerias em toda a extensão da Joaquim Felipe.

Observou-se, a partir de limites topográficos locais, que nem toda a Rua Joaquim Felipe drena para Avenida João de Barros, pois parte das águas pluviais são drenadas pelas sarjetas até a Rua João Fernandes Vieira, sendo conduzidas por meio de seu sistema de drenagem até o canal Derby-Tacaruna. Durante a visita à Rua Joaquim Felipe, verificou-se que, apesar de as condições topográficas e a rede de drenagem existente serem desfavoráveis, as causas dos alagamentos não podem ser atribuídas somente à falta de capacidade de captação de água das bocas de lobo ou da condução de água pelos condutos.

Percebeu-se uma significativa quantidade de lixo e sedimentos depositados nestas estruturas de drenagem, obstruindo assim a passagem das águas pluviais para os condutos. Isso porque, na rua em questão, existem faculdades e cursos preparatórios, além de comerciantes, que contribuem para o acúmulo de resíduos nestes elementos de drenagem (Figura 8 e Figura 9).
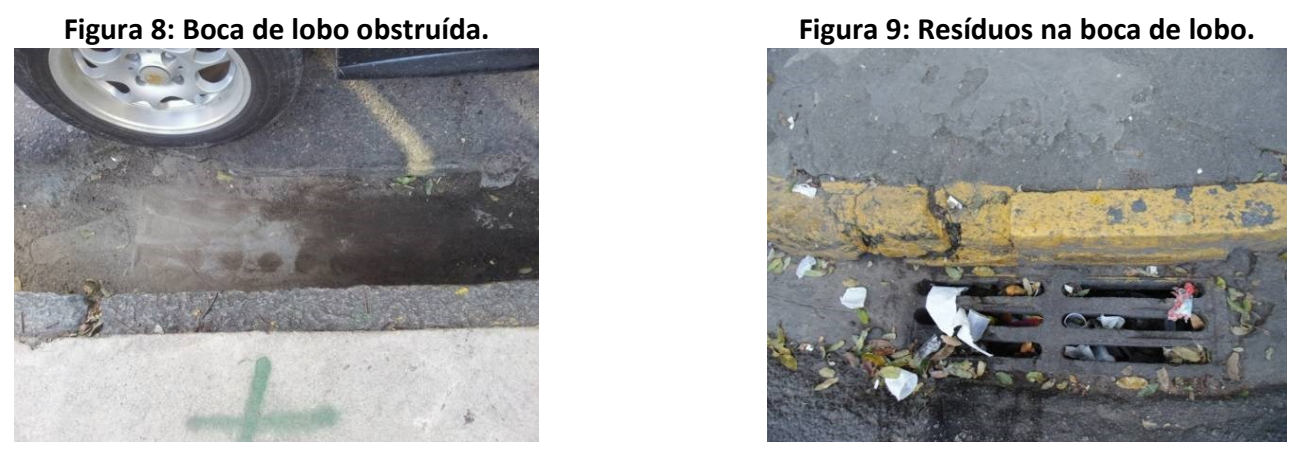

Além disso, trata-se de uma área bastante arborizada, o que exige uma maior atenção quanto aos serviços públicos de limpeza urbana, uma vez que se observou uma grande quantidade de folhas caídas e depositadas nos elementos de drenagem da via. Outro fator importante é que muitas árvores estão localizadas próximas às bocas de lobo, podendo ocorrer a invasão de suas raízes, provocando obstruções na estrutura (Figura 10 e Figura 11). 


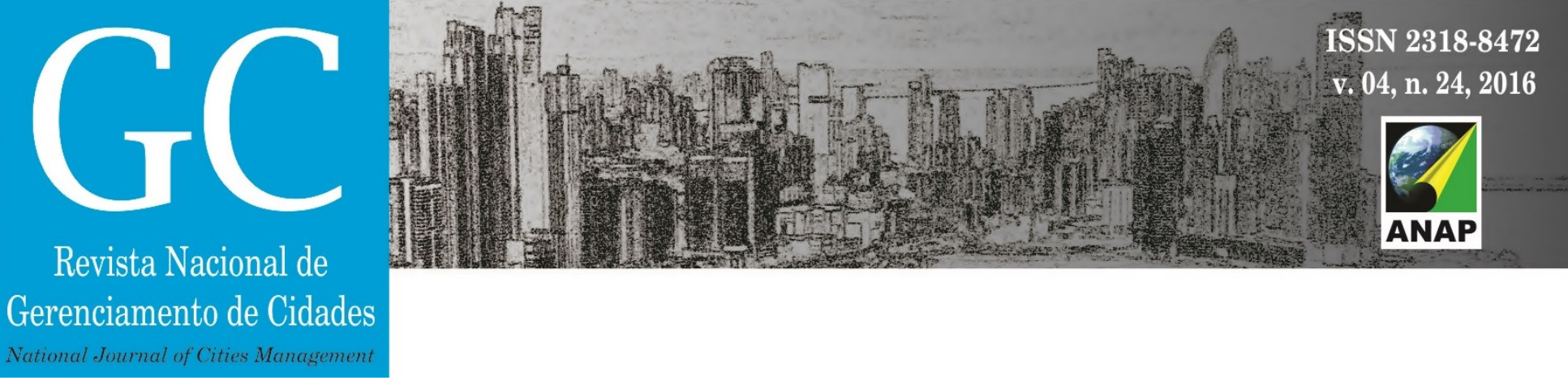

Figura 10: Presença de folhas secas em bocas de lobo.

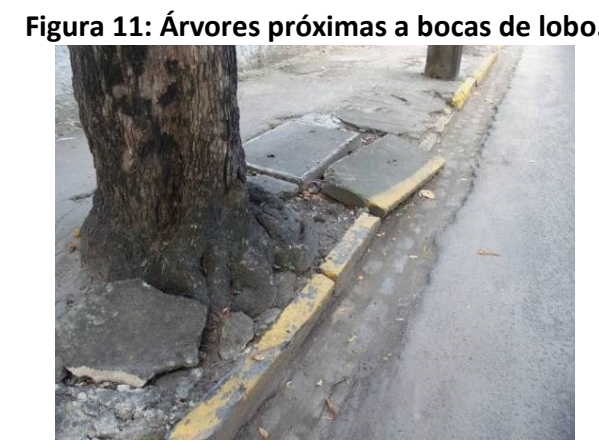

Alguns edifícios possuem drenagem direta para a rua, sem que haja uma detenção de parte do volume da água de chuva contribuinte à via, gerando, dessa forma, um incremento significativo de volume escoado pela rede de drenagem já deficiente (Figura 12). Verificou-se, ainda, a presença de esgoto a céu aberto, percorrendo pelas sarjetas e desaguando nas bocas de lobo, comprometendo ainda mais a eficiência do sistema de drenagem local (Figura 13).

A Figura 14 mostra um mapeamento realizado durante as inspeções de campo, a partir dos registros fotográficos dos elementos de drenagem identificados na área de estudo.

Figura 12: Ligação direta da drenagem do prédio na rua.

Figura 13: Presença de esgoto na rede de drenagem.
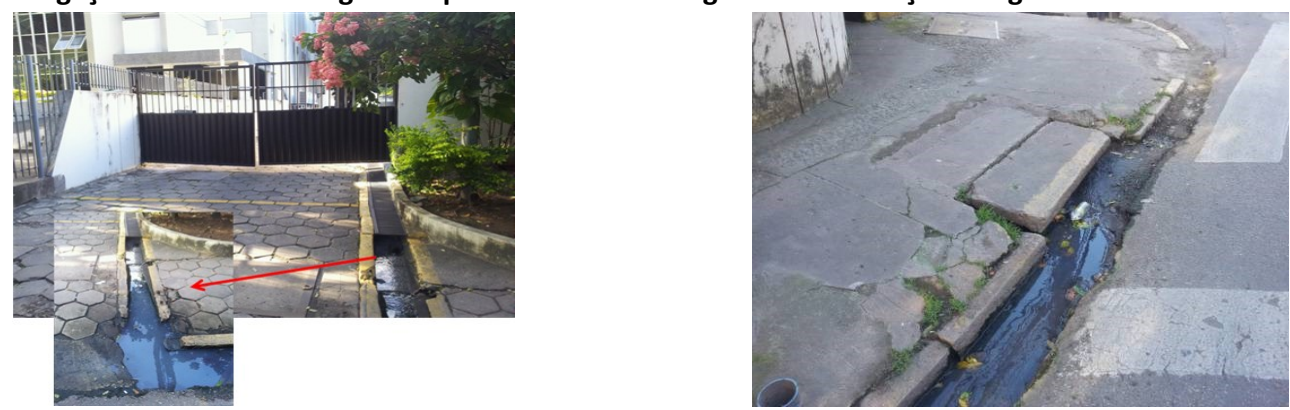


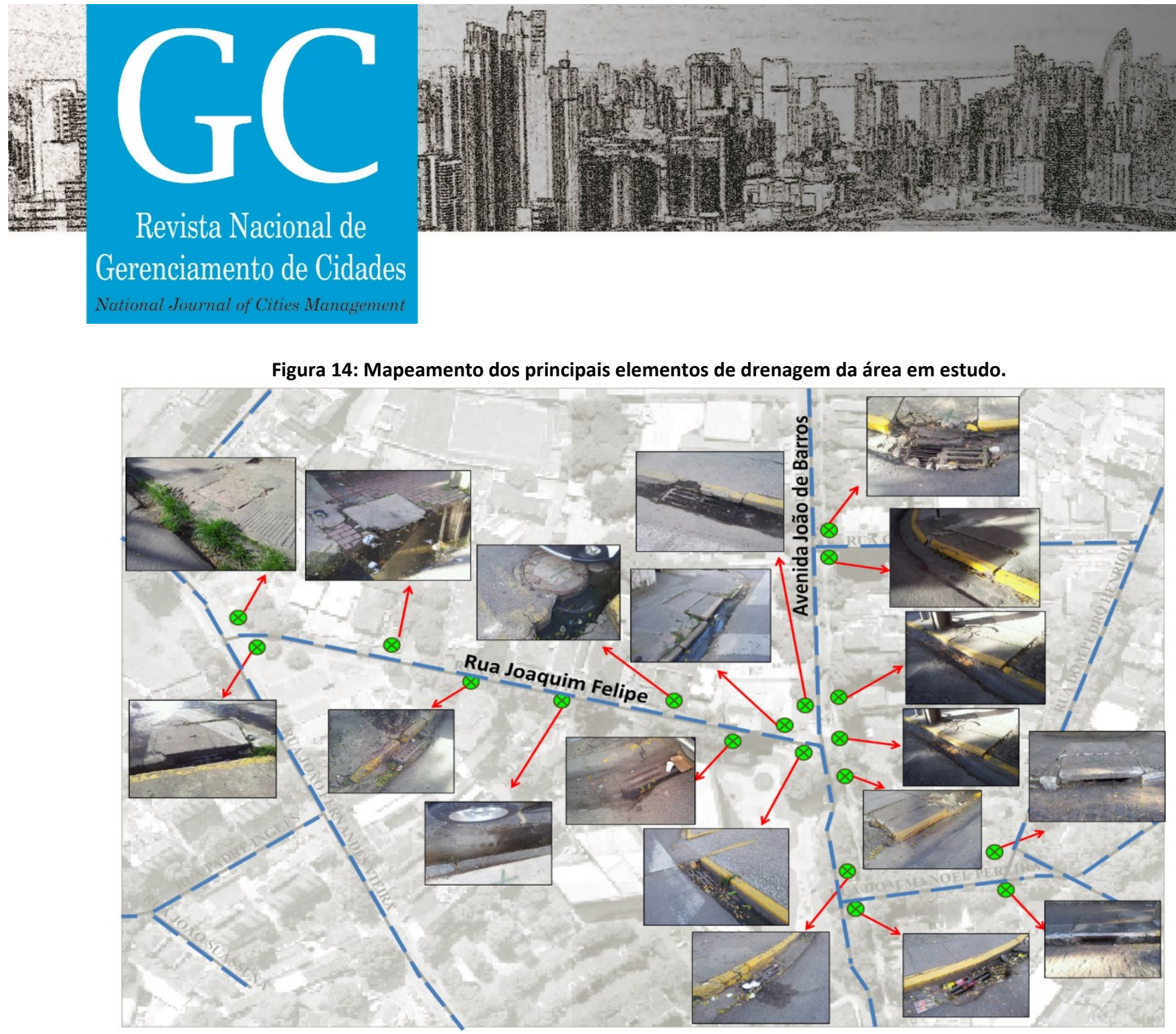

ISSN 2318-8472 v. 04, n. 24,2016

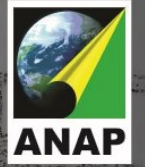

\section{Revista Nacional de}

\section{(Q) Bocas de lobo \\ - - $=$ Rua/Avenida}




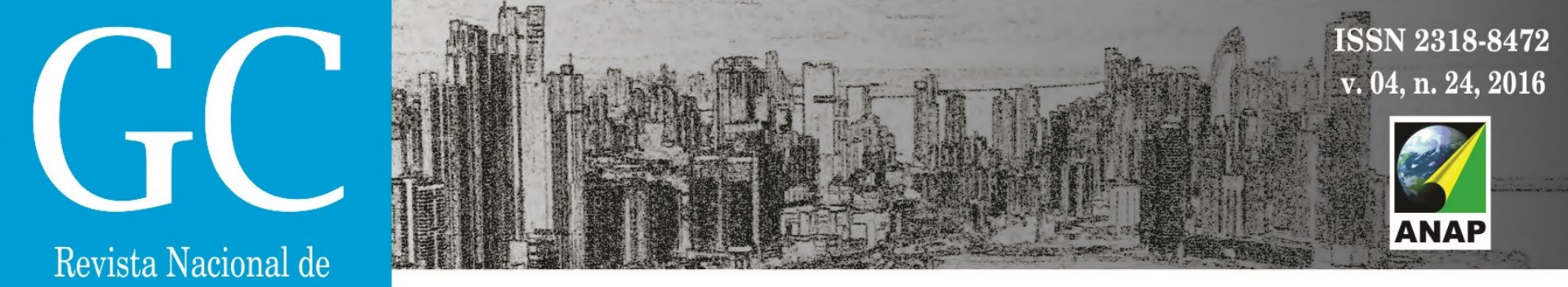

Gerenciamento de Cidades

\section{c) Reflexos de um evento de precipitação intensa no ponto crítico estudado}

Entre os dias 25 e 26 de junho de 2014, a Região Metropolitana do Recife sofreu com um evento extremo de precipitação, que causou vários transtornos à população. Segundo dados do Instituto Nacional de Meteorologia (Inmet), o total precipitado na estação automática Recife-303A entre $22 \mathrm{~h}$ do dia 25 e $18 \mathrm{~h}$ do dia 26 foi de $107,6 \mathrm{~mm}$, correspondente a $35 \%$ do total da média do mês de junho. A maior parte do total precipitado neste dia concentrou-se num curto período, tendo precipitado $66,80 \mathrm{~mm}$ entre $6 \mathrm{~h}$ e $10 \mathrm{~h}$ do dia 26 . Na oportunidade a maré estava baixa, atingindo a baixa-mar de $0,30 \mathrm{~m}$ às $9 \mathrm{~h} 45$ (Figura 15 ).

Figura 15: Gráfico com a relação precipitação x maré entre os dias 25 e 26 de junho de 2014.

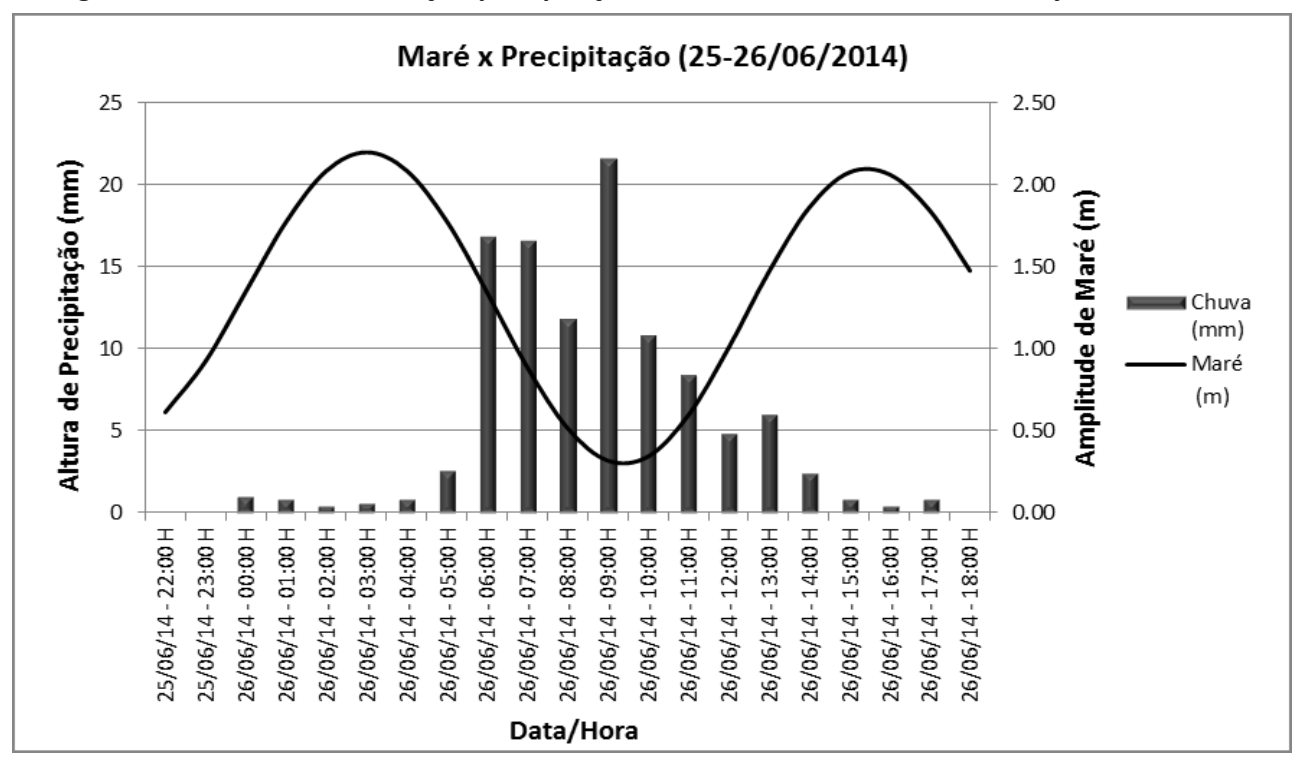

Os impactos desse evento refletiram-se principalmente na mobilidade urbana, com alagamentos em vários pontos estratégicos da cidade, que na oportunidade sediava uma das partidas de futebol da Copa do Mundo. As Figuras 16 e 17 mostram os efeitos deste evento no ponto crítico estudado. No momento da fotografia, registrada às $9 \mathrm{~h} 54$, já havia precipitado $73,20 \mathrm{~mm}$ (68\% do total precipitado neste evento) e a maré estava baixa. Essa situação provocou uma altura aproximada de alagamento de $14 \mathrm{~cm}$ acima do nível da calçada. 


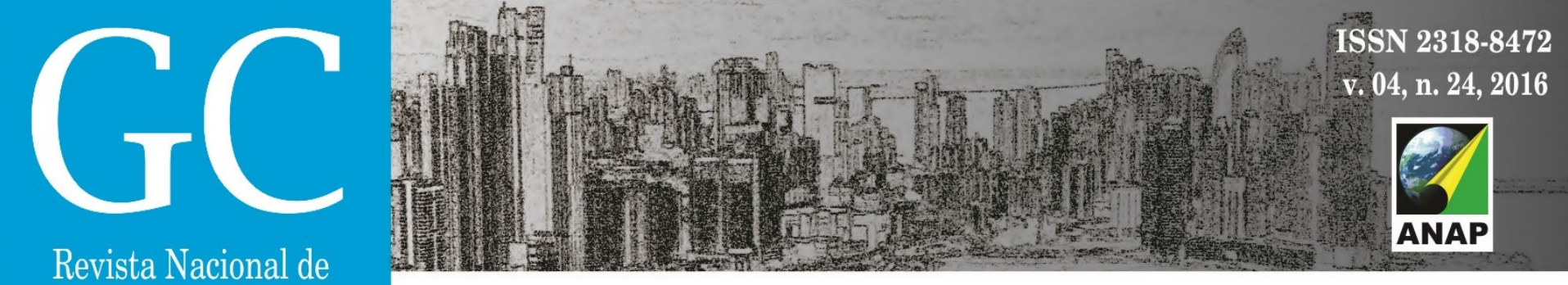

Gerenciamento de Cidades

em meio impresso. Além disso, foram feitos pela Emlurb, levantamentos topográficos complementares de alguns poços de visita, melhorando o dado cedido.

De posse do cadastro da área, uma das formas de se conhecer as condições de escoamento de uma rede de galerias de drenagem é através da sua representação em perfil longitudinal. A partir disto, é possível observar os trechos mais críticos, facilitando a definição de medidas que melhorem o escoamento ao longo da rede, através da definição de dimensões adequadas para os trechos da rede estudada, de modo a evitar os alagamentos.

A Figura 20 mostra o perfil longitudinal da galeria de drenagem, situada na Avenida João de Barros até a Rua do Príncipe, representando os trechos com problema de declividade e que interferem no deslocamento do fluxo do escoamento. Entre os poços de visita 1 e 17 os condutos circulares possuem diâmetros de $400 \mathrm{~mm}$ e o trecho de galeria a jusante do poço de visita 17 apresenta diâmetro de $600 \mathrm{~mm}$.

Figura 19: Perfil da galeria da Avenida João de Barros com a Rua do Príncipe.

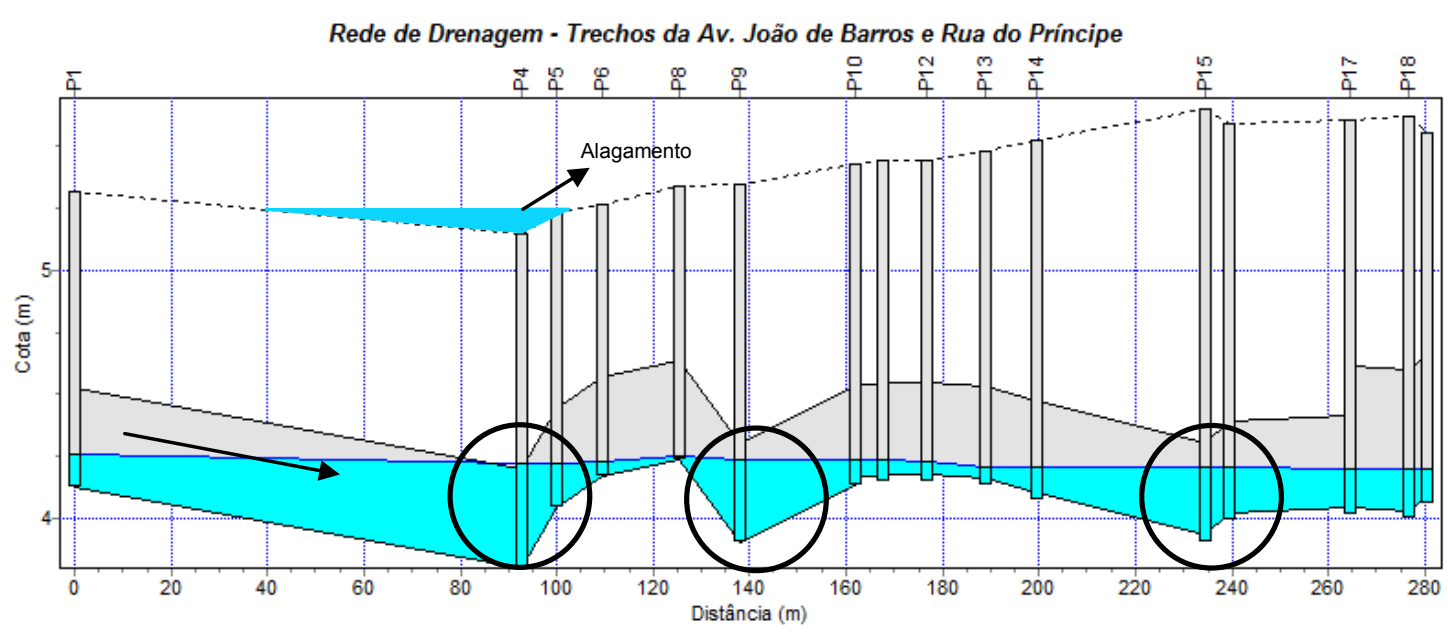

Estas diferenças de declividades no sentido inverso ao deslocamento do fluxo das águas provocam a retenção das águas pluviais nestes trechos, ocasionando o extravasamento da água, vindo a causar os alagamentos. Além disso, com essa configuração, é provável que haja uma deposição de sedimentos nos poços de visita com cotas de radiers mais baixas, causando uma diminuição na seção da galeria, dificultando ainda mais o fluxo do escoamento das águas nestes trechos, mais especificamente no poço de visita 4. É importante ressaltar esta junção "P4" recebe a galeria com diâmetro de 300 mm da Rua Joaquim Felipe, que, apesar de obstruída, aumenta um pouco mais a contribuição para este ponto. Esta irregularidade da rede existente pode ser uma das causas dos alagamentos recorrentes na área em estudo.

Conforme verificado na Figura 20, o maior desnível a ser vencido é de aproximadamente 24 $\mathrm{cm}$, num trecho de galeria com extensão de 7,30 m, representando assim, uma declividade negativa de $3,29 \%$. Este trecho encontra-se entre os poços de visita 4 e 5 , local este onde ocorre o alagamento estudado. 


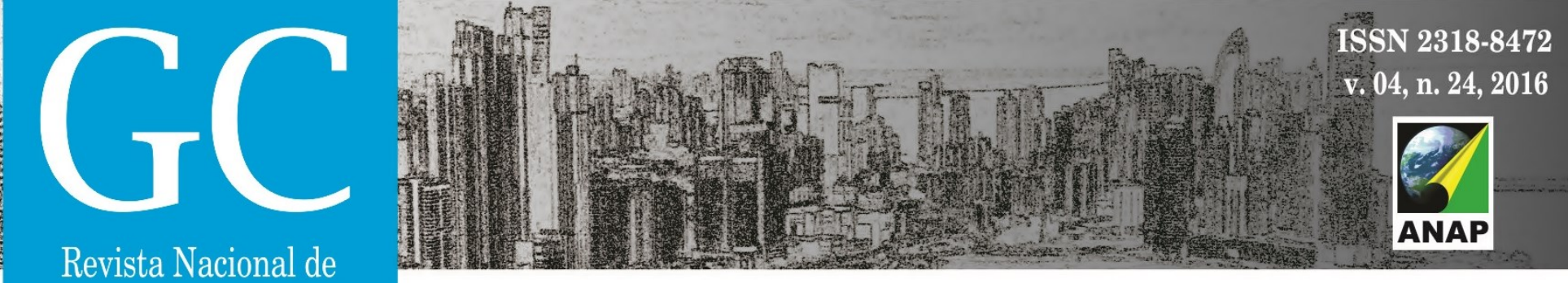

Gerenciamento de Cidades

Analisando as causas que provocaram o rebaixamento de alguns poços de visita, mais especificamente o "P4", possivelmente houve um recalque da estrutura, fazendo com que a cota de fundo deste poço de visita ficasse mais baixa em relação ao poço de visita de jusante, provocando, então, esta interferência no sentido do fluxo de escoamento das águas pluviais. Segundo Alheiros, Menezes e Ferreira (1990) esse fato é bastante comum na planície do Recife, que possui origem flúvio-marinha, apresentando depósitos de argila orgânica mole e média em cerca de $50 \%$ da área da planície, e muitas vezes com espessuras superiores a $15 \mathrm{~m}$. Visando uma solução para este trecho, é necessário, primeiramente, que sejam readequadas as cotas de fundo das galerias, permitindo que as águas pluviais possam escoar por gravidade, garantindo assim a eficiência do sistema de drenagem.

Além dos problemas de declividade, outra constatação é sobre as seções das galerias que compõe o sistema de drenagem local, encontrando-se subdimensionadas para as vazões afluentes. Isso se deve ao fato de que o sistema de drenagem do Recife foi concebido para atender a uma vazão afluente menor, quando o padrão urbanístico da cidade era outro.

\section{CONSIDERAÇÕES}

De posse de uma avaliação prévia do sistema de drenagem foi possível estabelecer medidas atenuantes aos problemas de alagamentos no ponto crítico estudado, a saber:

- Necessidade de verificação dos trechos obstruídos da rede de drenagem, pois este problema interfere na passagem do fluxo pela galeria. Após essa verificação, é necessária a limpeza dos condutos.

- É importante a realização da limpeza das ruas e calçadas diariamente, uma vez que na área em estudo existem faculdades e cursos preparatórios, além de comerciantes, como se verificou anteriormente;

- A manutenção das galerias e condutos de drenagem deve ser feitas mensalmente, pois o bairro é bastante arborizado;

- Incentivo ao uso de grelhas com manutenção sistemática, em substituição as bocas de lobo convencionais, impedindo desta forma, a entrada de resíduos sólidos que, quando não as entope, são conduzidos para os corpos receptores, contribuindo para a poluição dos cursos d'água e das praias;

- Evitar o bombeamento imediato da água de drenagem dos prédios situados na Rua Joaquim Felipe, no momento em que está chovendo, recorrendo às técnicas de retenção da água, reduzindo dessa forma, o incremento do volume de água produzido por um determinado evento de precipitação.

- Faz-se também necessário o controle efetivo da urbanização, evitando a impermeabilização excessiva das poucas áreas de solo exposto ou com vegetação, identificados na área de contribuição ao ponto de alagamento. 


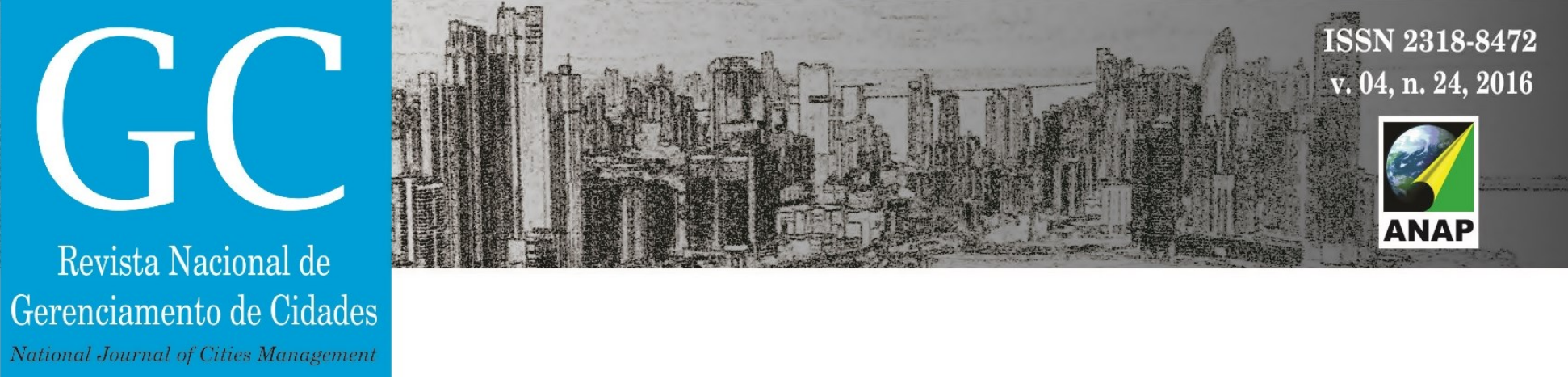

- É importante também, que os prédios na situados nesta área estabeleçam dentro do lote: a) um reservatório de armazenamento de água de chuva para utilização ou b) para amortecimento de vazões ou c) uma trincheira de infiltração. O uso de microrreservatórios de detenção em nível de lote apresenta-se, então, como uma das possibilidades para a redução dos picos de cheia e consequentemente alagamentos, mostrando também que pode servir como um acumulador de águas pluviais para posterior reuso.

\section{REFERÊNCIAS BIBLIOGRÁFICAS}

ALHEIROS, M. M.; MENEZES, M. F.; FERREIRA, M.G. (1990). Carta Geotécnica da Cidade do Recife, Sub-Área Geologia / Geologia de Engenharia, Relatório Final de Atividades. FINEP / UFPE, 81 p.

FOLHAPE. Chuvas provocam retenções e alagamentos em vários pontos do Recife. Disponível em: http://www.folhape.com.br/cms/opencms/folhape/pt/cotidiano/noticias/arqs/2013/07/0015.html. Acesso em: 10 dez. 2015.

IBGE. Censo Demográfico de 1991. Disponível em: <http://www.ibge.gov.br>. Acesso em: 20 fev. 2016.

Censo Demográfico de 2000. Disponível em: <http://www.ibge.gov.br>. Acesso em: 20 fev. 2016.

Censo Demográfico de 2010. Disponível em: <http://www.ibge.gov.br>. Acesso em: 20 fev. 2016.

JC ONLINE. Disponível em: http://ne10.uol.com.br/canal/cotidiano/jc-transito/noticia/2013/05/17/ruas-e-avenidasdo-grande-recife-ficam-alagadas-com-a-chuva-348642.php. Acesso em 01 nov. 2013.

LEIAJÁ. Ruas do Recife sofrem com alagamentos após chuva. Disponível em: http://www.leiaja.com/noticias/2013/ruas-do-recife-sofrem-com-alagamentos-apos-chuva/. Acesso em: 10 dez. 2015.

RECIFE. Lei no 16.176, de 09 de abril de 1996: Estabelece a Lei de Uso e Ocupação do Solo da Cidade do Recife. Disponível em: http://www.legiscidade.recife.pe.gov.br/lei/16176/. Acesso em: 15 de março de 2016.

SILVA JUNIOR, M. A. B., 2015. Alternativas compensatórias para controle de alagamentos em localidade do RecifePE. Dissertação (Mestrado). Escola Politécnica, Universidade de Pernambuco.

SILVA, G. B. L. Avaliação experimental sobre a eficiência de superfícies permeáveis com vistas ao controle do escoamento superficial em áreas urbanas. 2006. 199 f. Tese (Doutorado em Tecnologia Ambiental e Recursos Hídricos). Departamento de Engenharia Civil e Ambiental, Universidade de Brasília, Brasília, 2006.

YANNOPOULOS, S. I.; GRIVAKI, G.; GIANNOPOULOU, Io.; BASBAS, S.; OIKONOMOU, E. K. Environmental impacts and best management of urban stormwater runoff: measures and legislative framework. Global NEST Journal, v. 15, n. 10, p. 324-332, 2013. 